\title{
Relieving Grid by Adding PV and BESS for Economical Charging of EV in the Charging Station
}

\author{
Dol Raj Kunwar*, Bijay Sharma, Sunil Paudel, Tanka Nath Ojha, Menaka Karki \\ Department of Electrical Engineering, Pashchimanchal Campus, IOE, TU, Pokhara, Nepal \\ Email address: \\ astod38@gmail.com (D. R. Kunwar),menaka@wrc.edu.np (M. Karki) \\ ${ }^{*}$ Corresponding author \\ To cite this article: \\ Dol Raj Kunwar, Bijay Sharma, Sunil Paudel, Tanka Nath Ojha, Menaka Karki. Relieving Grid by Adding PV and BESS for Economical \\ Charging of EV in the Charging Station. American Journal of Computer Science and Technology. Vol. 3, No. 1, 2020, pp. 7-17. \\ doi: $10.11648 /$ j.ajcst.20200301.12
}

Received: December 23, 2019; Accepted: February 3, 2020; Published: April 14, 2020

\begin{abstract}
Being fueled by electric power, electric vehicles (EVs) are the sustainable alternatives to the conventional vehicles: EVs are likely to alleviate the environmental pollution brought out by excessive use of fossil fuels. To realize electric locomotion, there should be efficient charging facility in our electrical infrastructure to charge the batteries of the EVs. This work proposes an effective topology that focuses to reduce the stress on the grid due to overlapping of EV load profile with the normal Grid-electricity load profile in technically as well as financially feasible way. The EV's owner can charge his/her vehicle up to desired SOC level from the charging station with sources: PV, BESS and Grid. Here, BESS is a massive energy storage system that can store energy from the grid as well as from the PV system which supplies power to the load during daytime. BESS supplies the load during the peak of the system and helps the grid relieve as well as reduce the Grid-electricity bills during peak hours. Regulation of EV load sharing and prevention of mismatch between circulating currents supplied by power sources is implemented using fixed droop method. The trend of power demand of EVs throughout a day in a charging station is assumed in accordance with the other related works. The economic feasibility of the proposed system is verified in terms of the payback period of the investment made on the PV and BESS. The simulations are successfully implemented to validate the effectiveness of the system and to demonstrate the load management.
\end{abstract}

Keywords: Electric Vehicle Charging, Power Flow Management, Droop Method

\section{Introduction}

Currently, transport sector endures significant challenges regarding the energetic model based on fossil fuels. In fact, $69.2 \%$ of the oil consumed in the world in 2018 was due to the transport sector [1]. A typical passenger vehicle emits about 4.6 metric tons of carbon dioxide per year [2]. This dependence and the excessive use of fossil fuels implies numerous issues: environmental problems such as climate change and air pollution, economic problems due to exorbitant oil prices and geopolitical problems such as a strife between countries regarding mines of oil products. In this scenario, electric vehicles (EVs), could be a sustainable alternative to internal combustion engine (ICE) vehicles powered by oil; since, an EV is innervated by battery which implies the clean energy. However, the market penetration of electric vehicles (EVs) has been an iota [3]. This is because of the trivial availability of charging facilities along with the large time period of charging. From the perspective of the electricity grid, a longer EV peak load period can potentially overlap with the normal grid electricity peak load period, resulting high stress on the grid whose consequences can be seen as contingency of power system network [4]. One way to alleviate the stress on the grid is to change the load curve of the EV by either changing the driving pattern and mobility of EVs or altering the charging pattern of EVs in the station providing them an order of priority-wise charging such as to reduce stress on the grid [5]. An odd with this method is its complexity. Another method is to charge the vehicles in accordance with the charging time slots created by considering both the utility load profile condition and vehicle load demand [6]. Thus, this is the way of charging electric Vehicle by variable power supply; but, charging with variable power supply is less efficient and incurs the polarization problem. That's why charging with constant 
power is prominent. Many researchers have proposed smart charging strategies to reduce the stress on the grid due to large penetration of electric vehicles in the power market [7, 8]. But the limitations for this concept is that there is still the problem of slow charging thus the time problem is quite bulky. Amending the renewable energy sources like PV with the grid, and managing the power flow among them engenders an effective way of charging which might facilitate the fast charging too [9].

This paper presents an idea to introduce renewable energy sources like PV with the Grid backed by battery energy storage system (BESS) in charging station and manage these power sources in accordance with varying load demand from electric vehicles for the economical charging of electric vehicle in the charging station. This paper focuses on to the use of RES for reducing the stress on the Grid due to high power demand from electric vehicle for charging and consequently to reduce the tariffs to be paid to the Grid; because, the tariff is very high due to bulk power consumption from the vehicles in the peak period when the tariff rate is highest one in accordance with the Time of Use (TOU) tariff. Upon adding the PV and BESS in the existing Grid based charging station obviously increases the investment cost of it; however, this investment can be returned by the income generated by the charging station: from economical charging of electric vehicle. The proposed method reduces the Grid power consumption during peak hours (highest tariff rate) as well as during the off-peak hour (moderate tariff rate) and super-off-peak hour is utilized to consume high power from Grid for innervating the BESS which will be discussed later. It is expected from the work to bring advancement over the traditional Grid-only charging method of EVs, and introduces some effective method of power flow management using Droop regulation in DC bus. The outline of the work includes following sections: section 2 which presents the related works that has been contributed by different authors, the third section includes the proposed framework for load sharing among PV, BESS and grid. The control of Dc-link current and load sharing among the sources, implemented by droop regulation, is presented in this section. Furthermore, the power flow management algorithm along with the method of economic analysis is expounded in third section. Section four of the paper comprises MATLAB design and specification of the sources involved and modeling of EV load profile, the MATLAB simulation results of the proposed system are included along with the economic analysis in section five whereas section six concludes the work.

\section{Related Works}

Reference [10] proposed the charging processes in uncoordinated and coordinated manner. In uncoordinated charging, the charging process is performed at on-board charger power rating without any control. Coordinated charging meets the expectation of both the utility operators and EV users. [11] had proposed smart charging, which contributes in peak shavings and valley fillings. The centralized and decentralized control strategies are also proposed as the methods of smart charging.

Grid tied PV-battery hybrid technology is proposed by [12], which supports the reduction of the stress on the grid line due to overloads. A probabilistic model has been proposed by [13], which presents complete mobility patterns of EVs in order to estimate an expected load in the system which will be discussed in the upcoming section. Simulation and analysis of photovoltaic system with boost converter is proposed and presented by [14] where the idea of controlling the output voltage of the PV is presented by tuning a PI controller. Similarly, reference [15] proposed multi-source model and developed a control algorithm for EV charging. It also presented real time monitoring of power demand and supply.

A work in reference [3] conveys the information to the extent the grid has to bear a stress due to the semblance of EV load profile with the normal residential load profile. It is obvious from the work that the vehicles are in the driving phase during the day and at the other time there are trivial numbers of vehicles seen in the road. Figure 1 shows the traffic distribution during the day time in an urban area in New South Wales (NSW), Australia. The electric vehicle distribution in the road is obviously the same as the normal vehicle distribution; that's why, the figure can be realizes equally to the electric vehicle too. It shows that the traffic count is smaller in the evening time after $5 \mathrm{pm}$. That's why it us conspicuous that the larger number of electric vehicles are parked in the charging station in the evening time than at the day time. Consequently, the load demand by electric vehicle for charging is larger during evening than during the day time.

Figure 2 depicts the average load profile of Nepal in Chaitra month of 2073 (BS) [16]. It shows that the electricity load consumption is larger during the evening 5 pm onwards which is commonly known as the peak period. Upon juxtaposing the two figures (traffic counts and Electricity load profile), the distribution of load demanded by EV over time and that of the normal residential load overlaps: the peak period of both the load profile coincides. This consequently brings a huge stress on the grid.

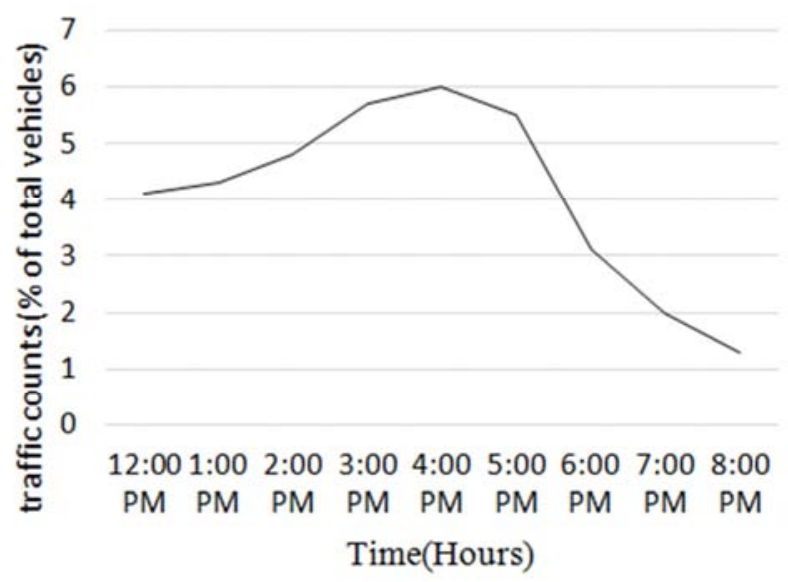

Figure 1. Traffic counts in a typical day as percentage of total vehicles. 


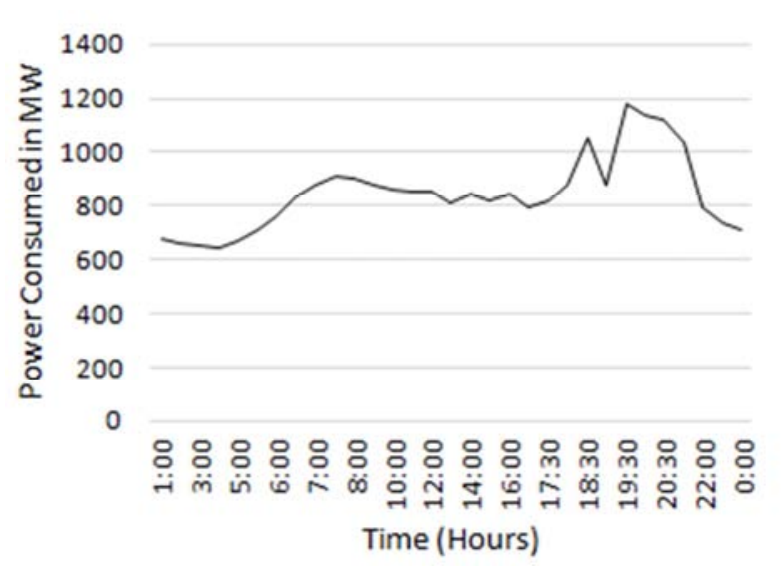

Figure 2. Consumer Load profile of Grid-Electricity.
To reduce stress in the grid, power demand by EV is to be supplied by PV and BESS by adopting an optimization algorithm, where priority wise selection of sources is to be implemented. By using BESS to share load with grid, the stress on the grid can be reduced significantly during the peak period. the management of power flow between the sources: PV, BESS and grid can be implemented on the time of day basis which will be elaborated later.

When multiple power sources are connected in parallel for supplying common load, the load sharing in dc power system is to be regulated. Reference [17] proposed current sharing control of parallel boost converters based on droop index. Droop regulation method for load sharing has been commonly used in different literatures $[18,19]$.

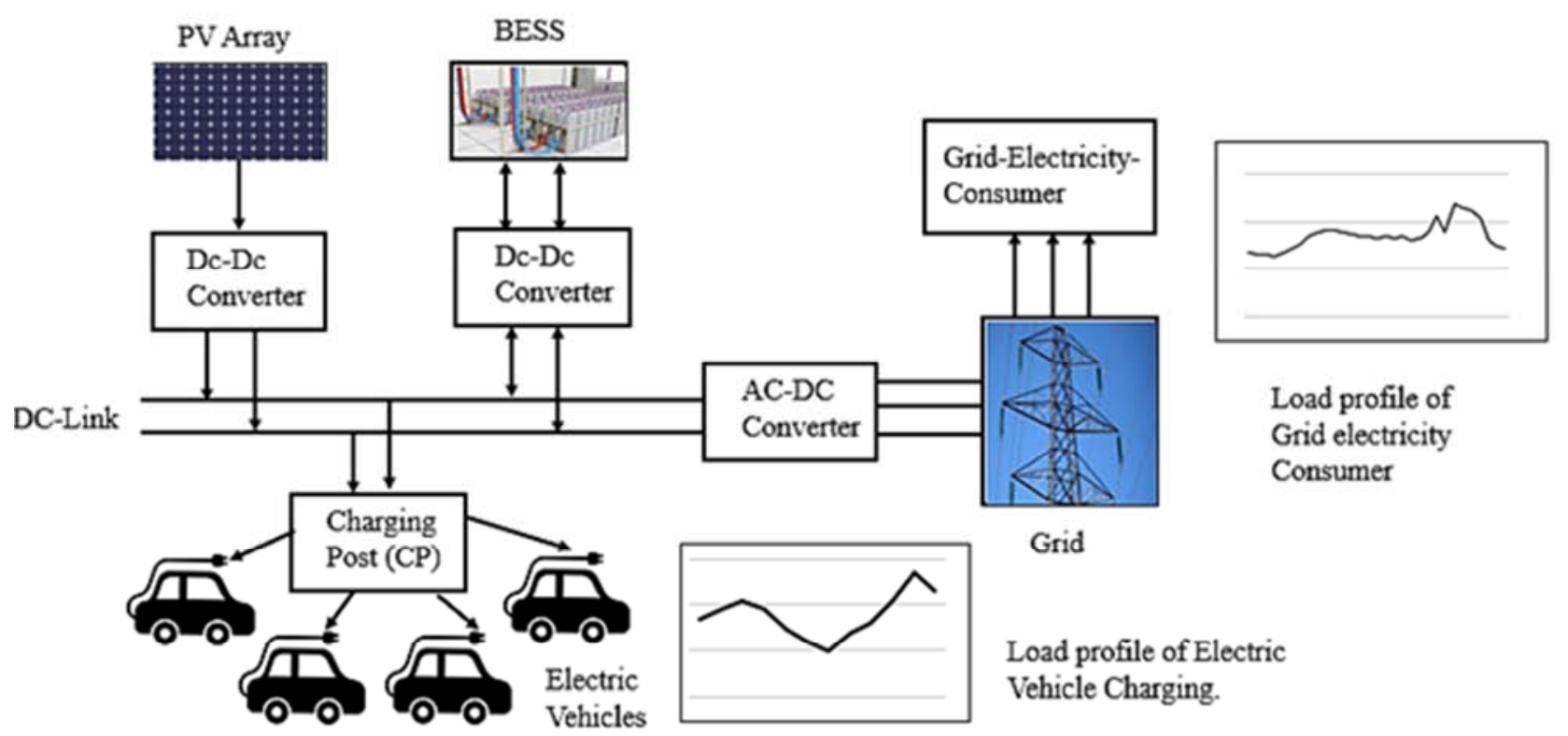

Figure 3. Proposed System for Charging of Electric vehicle.

\section{Proposed Framework for EV Load Sharing Among PV, BESS and Grid}

This section develops a system framework showing the electrical connection among the sources (PV, Battery and the grid) and the loads (EVs charging stations, AC loads and DC loads). Figure 3 clarifies basic requirement for the system proposed in this research. It consists of a grid tied PV with battery. The PV array is connected to the dc link via its dc-dc boost converter known as the dc booster in order to support the faster charging. BESS is used to deliver the part of peak load which significantly reduces the stress on the grid during peak time. Next, the battery energy storage system can supply the electrical power to the DC-link through the boost converter. The grid electricity is also fed to the DC-link via AC/DC converter. This way the DC-link is fed with three sources. When an EV is plugged in to the charging post (CP), it withdraws the power from the DC-link. A suitable power management technique has been proposed to prioritize the source of electrical power to the charging stations. First priority would be the PV source. Second priority would be the battery energy storage system. The major advantage of using battery energy storage system is that it can store electrical energy from the grid at the time of the day when the electricity tariff is low as well as from the excessive power produced by PV in the day time and supplies the load in the time when electricity tariff is high to reduce stress on the grid as well as the overall energy cost of the charging station. The number of charging posts in a station depends upon the capacity of the station.

\subsection{Electric Vehicle Charging}

Existing PEV charger hardware and technologies allow charging at either coordinated or uncoordinated manner. Uncoordinated charging strategy is used as it allows charging of EV at charger power rating continuously [20]. Once an EV is parked in charging station and is plugged in for charging, kwh demand of EV depends on its SOC level and is equivalent to following relation: 


$$
\mathrm{E}_{\mathrm{ch}, \mathrm{i}}=\frac{\left(1-\mathrm{soc}_{\text {initial }, \mathrm{i}}\right) \mathrm{C}_{\mathrm{B}, \mathrm{i}}}{\eta}
$$

Where, $\mathrm{E}_{\mathrm{ch}, \mathrm{i}}$ is the charging kwh demand by the $\mathrm{EV}$, $\mathrm{SOC}_{\text {initial,i }}$ is the state of charge at the time of arrival, $\mathrm{C}_{\mathrm{B}, \mathrm{I}}$ is the nominal battery capacity, and $\eta$ is on-board charger efficiency.

Total time taken for full charge of battery of EV after it is plugged in is estimated as:

$$
\mathrm{T}_{\mathrm{ch}, \mathrm{i}}=\frac{\mathrm{E}_{\mathrm{ch}, \mathrm{i}}}{\mathrm{P}_{\mathrm{i}, \text { rated }} \times \eta}
$$

Where, $\mathrm{P}_{\mathrm{i} \text {, rated }}$ is the rated power $(\mathrm{kW})$ of $\mathrm{i}^{\mathrm{th}} \mathrm{EV}$.

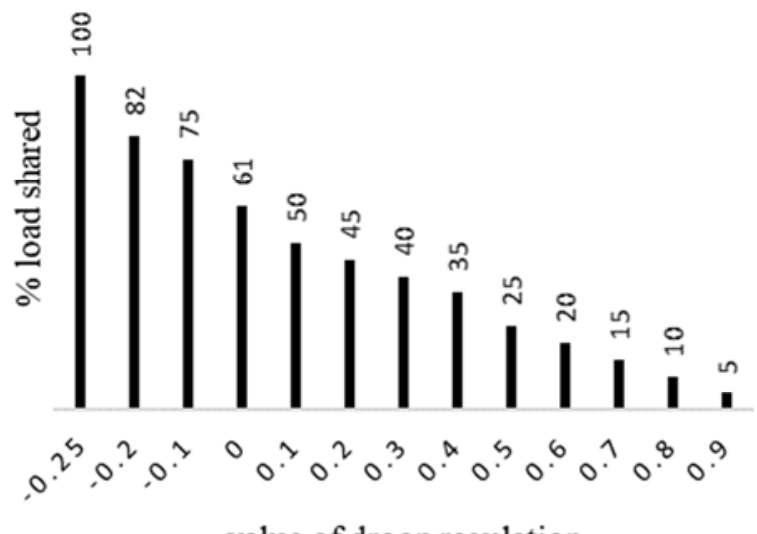

Figure 4. Droop regulation characteristics of $P V$ when $P V$ and Grid are.

\subsection{Load Sharing in Parallel Connected Sources}

All change in the terminal voltage of the converters is carried out as per the load to be shared by their corresponding sources, and it's called droop regulation. Load sharing is modeled based on the interpolation of the droop characteristics as per the percentage load to be shared. Figure 4 shows the droop characteristics of the PV when all the sources are on. It shows the variation of change in voltage as per the load to be shared. Based on the interpolation from the curve for the required sharing of load, the value of droop regulation is found out.

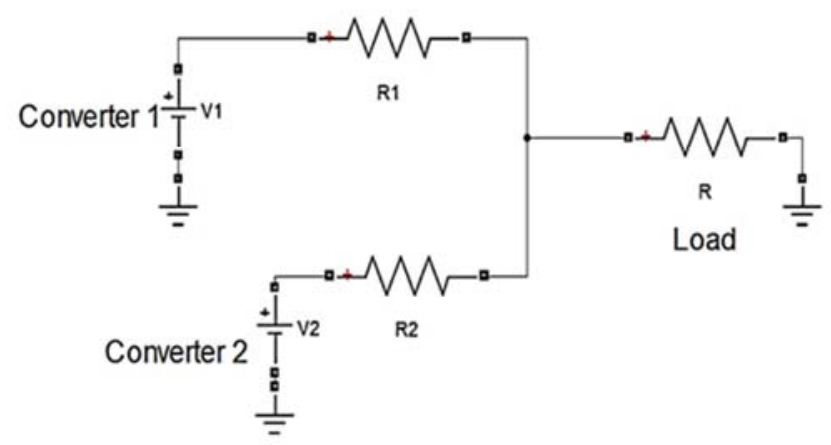

Figure 5. Circuit realization of load sharing between two parallel connected sources.
When the converters are connected in parallel, they share load in accordance with their voltage output and overall resistance of the converter. when load is switched on/off suddenly, there is mismatch in converter output voltage because each converter tries to deliver the load. Which's why the circulating current will increase significantly, as each converter switch try to increase the share of current and this causes overloads in converters.

Figure 5 shows a simplified diagram of two parallel connected converters. Output voltages, currents and resistances of the converter- 1 and converter- 2 are represented by $\mathrm{Vdc} 1$ and $\mathrm{Vdc} 2, \mathrm{I} 1$ and $\mathrm{I} 2$, and $\mathrm{R} 1$ and $\mathrm{R} 2$ respectively. By applying Kirchhoff's Voltage law in converter circuits, following relations can be established [21].

$$
\begin{aligned}
& V_{d c 1}-I_{1} R_{1}-I_{L} R_{L}=0 \\
& V_{d c 2}-I_{2} R_{2}-I_{L} R_{L}=0
\end{aligned}
$$

Expressions for output currents from each converter can be derived from above equations as:

$$
\begin{gathered}
I_{1}=\frac{\left(R_{2}+R_{L}\right) V_{d c 1}-R_{L} V_{d c 2}}{R_{1} R_{2}+R_{1} R_{L}+R_{2} R_{L}} \\
I_{2}=\frac{\left(R_{1}+R_{L}\right) V_{d c 2}-R_{L} V_{d c 1}}{R_{1} R_{2}+R_{1} R_{L}+R_{2} R_{L}} \\
I=I_{1}+I_{2}
\end{gathered}
$$

The circulating current and overload load to the converter can be minimized by adding a droop regulation resistor $\mathrm{R}_{\text {droop }}$ to each converter. By adding $\mathrm{R}_{\text {droop1 }}$ and $\mathrm{R}_{\text {droop2 }}$ in series with each converter, current sharing by individual converter can be improved. Droop resistor decreases the terminal voltage of each converter and minimizes the mismatch in current sharing.

Droop regulation is implemented by adding or subtracting value, equivalent to droop resistor voltage drop, from the reference voltage given to each converter's PID controller so that it could fix the output voltage of each converters in accordance with the percentage of load to be shared by them. Value of reference voltage of each PID controllers is calculated as:

$$
\begin{aligned}
& \mathrm{V}_{\mathrm{ref} 1}=-\mathrm{m}_{1} \mathrm{P}_{1}+\mathrm{V}_{\mathrm{NL}} \\
& \mathrm{V}_{\mathrm{ref} 2}=-\mathrm{m}_{2} \mathrm{P}_{2}+\mathrm{V}_{\mathrm{NL}}
\end{aligned}
$$

Where, $\mathrm{V}_{\mathrm{NL}}$ is the no load constant voltage, $\mathrm{m}_{1}$ and $\mathrm{m}_{2}$ are droop regulations obtained from slope of the voltage vs power plot. Value of $\mathrm{m}_{1}$ and $\mathrm{m}_{2}$ are calculated continuously as per the change in load demand by using interpolation method in which slope of droop characteristics is calculated according to the load to be shared.

Here, $\mathrm{m}_{1} \mathrm{P}_{1}$ and $\mathrm{m}_{2} \mathrm{P}_{2}$ is the value of voltages to be changed $(\Delta \mathrm{V} 1$ and $\Delta \mathrm{V} 2)$. Value of $\Delta \mathrm{V} 1$ and $\Delta \mathrm{V} 2$ are formulated from the characteristics of percentage load shared vs value of droop regulation $(\Delta V)$. 


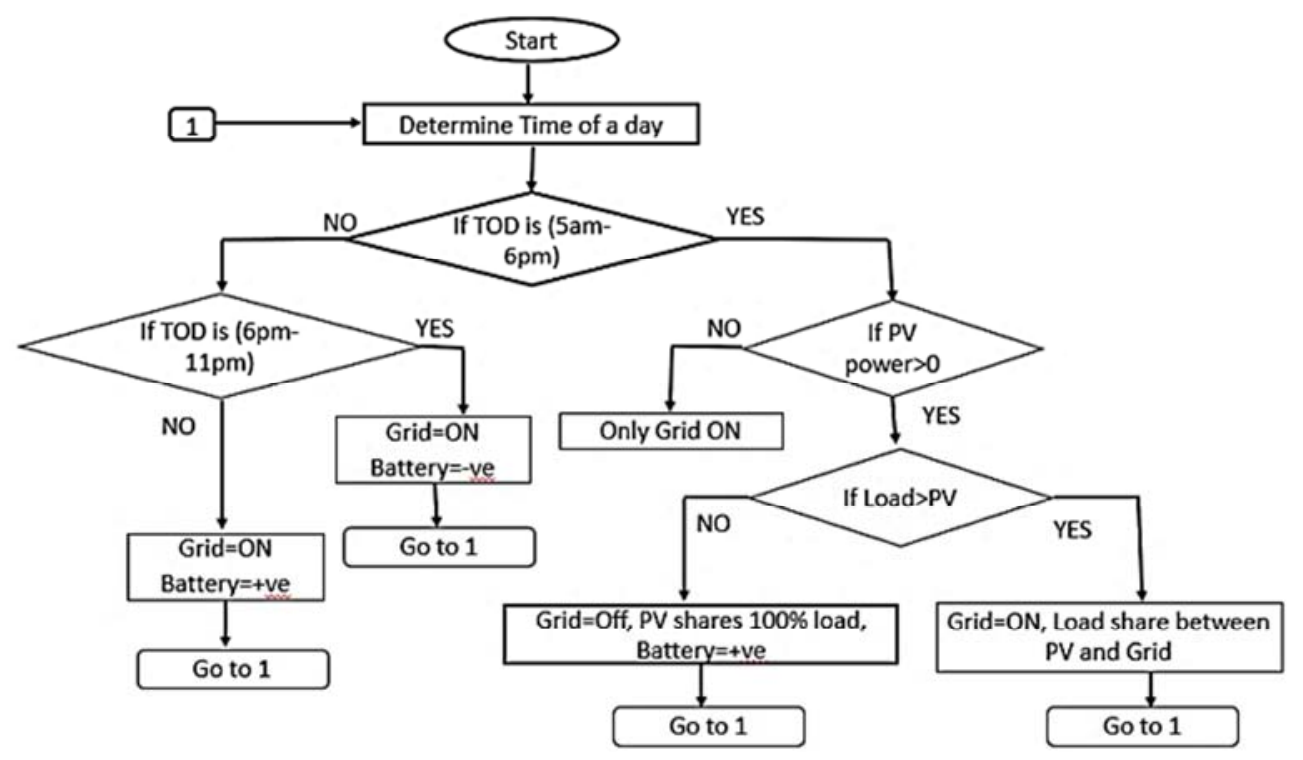

Figure 6. Flow Chart for Power Flow management Algorithm.

\subsection{Power Flow Management Algorithm}

Load demand of EV keeps on changing with time. For the different power demands PV, battery and Grid are scheduled using the algorithm as per the flow chart shown in Figure 6. it shows priority wise selection of sources either alone or in combination depending on the loads. Algorithm is simulated so as to provide highest priority to PV and it goes on decreasing from Battery to Grid. Scheduling is done such that PV power is fully utilized and so like for battery according to priority.

For a specific load, the combination of sources to supply the load demand depends on the time of a day. During the day time $(5 \mathrm{am}-6 \mathrm{pm})$, solar energy is available for the power generation from $\mathrm{PV}$ and its power generation also varies with time due to the variation of temperature and irradiances with time of day. PV power generation is compared with the load demand. If $\mathrm{EV}$ power demand is higher than $\mathrm{PV}$ can provide, then Grid is made ON and PV shares load with Grid. Similarly, if Load demand at a specific time is less than PV power generation at that time, PV solely supplies the demand. Also, the PV power remained after supplying EV loads is utilized to charge the BESS. During the night time (11pm-5am), the Grid electricity tariff is lowest and hence BESS is charged at that time. Since, no power is generated from PV during night, so Grid supplies EV loads as well as BESS charging load. During the peak load demand time $(6 \mathrm{pm}-11 \mathrm{pm})$, there is no $\mathrm{PV}$ power generation, and there is large stress on the Grid due to high power demand from EVs. Also, the Grid electricity tariff is very high, that's why fully charged BESS is discharged to share load with Grid. By following the algorithm, continuous power availability for uncoordinated charging of EVs is implemented.

\subsection{Economic Analysis}

The economics of the cost the whole system involves two types of costs: initial investment cost and operating cost which includes maintenance cost and energy cost. While the economics of the revenue of the system involves only the revenue from energy selling that the energy price paid by the owners of electric vehicles. For the project to be economically feasible, the payback period of the system must be as lower as possible. The investment cost includes the cost of installation of PV and BESS. The economics of PV includes the investment cost of the PV based on California residential value of $\mathrm{PV}$ installation that is $\$ 3.5$ per $\mathrm{KW}$ size of PV array [22]. Similarly, the economics of BESS includes the investment of $\mathrm{Li}$-ion BESS based on the 2020 price estimation release by Korea Battery Industry Association in 2017 [23]: \$200 per kWh. Likewise, the energy cost per kWh is used as that implemented by The Ontario Energy Board in 2019 [24]: based on Time of a day.

Table 1. Tariff rate according to Time of Use.

\begin{tabular}{ll}
\hline Time of a Day & Tariff rate $\mathbf{( \$ / k W h )}$ \\
\hline $17-23$ & 0.208 \\
$23-05$ & 0.101 \\
$05-17$ & 0.144 \\
\hline
\end{tabular}

The purpose behind the economic analysis is to find out whether the adding of PV and BESS in the existing mere Grid-based EV charging is economically feasible that is whether the payback period of the investment made on PV and BESS is realizable. For this analysis, the other associated installation costs such as labor cost, cost of land, cost of Grid connection, etc. can be disregarded. So, the following relations can be established:

Investment=installation cost of PV + BESS cost

Annual revenue $=$ Energy charge paid by the EV owners as per the price per $\mathrm{kWh}(\$ 0.151 / \mathrm{kWh}$ : Based on assumption as it varies between states from $\$ 0.08 / \mathrm{kWh}$ in Idaho to $\$ 0.33 / \mathrm{kWh}$ in Hawaii. [25])

Annual cost: Energy consumed from Grid (based on Tariff rates of NEA) 
Annual profit: Annual revenue - Annual cost

Simple Payback period $=\frac{\text { Annual Profit }}{\text { Initial Investment }}$

By the proposed system of EV charging, the stress on the grid can be reduced significantly and this eventually reduces the annual cost of electricity the station has to pay to the electricity authority. Annual profit can be used to find out the payback period of the investments made on PV and BESS.

\section{Modeling of Components}

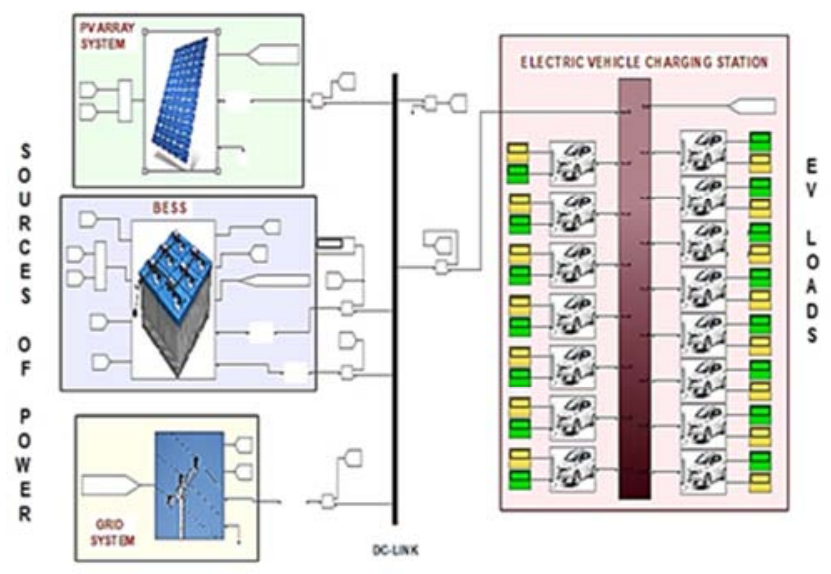

Figure 7. MATLAB Simulink Model of the proposed system.

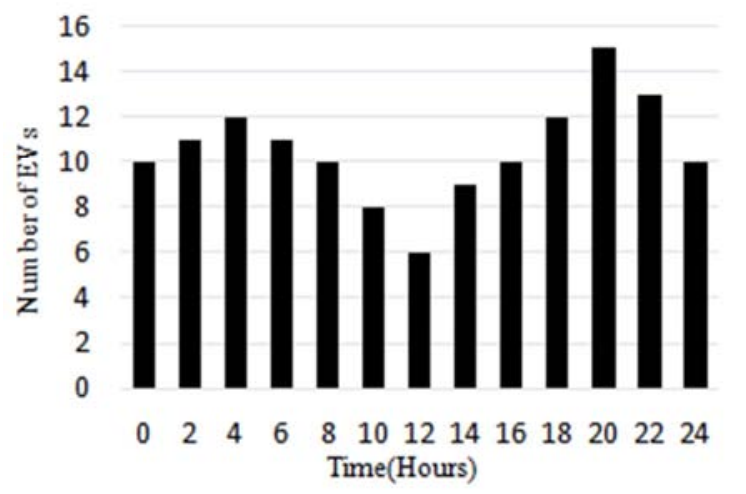

Figure 8. Distribution of estimated number of electric vehicles with time.

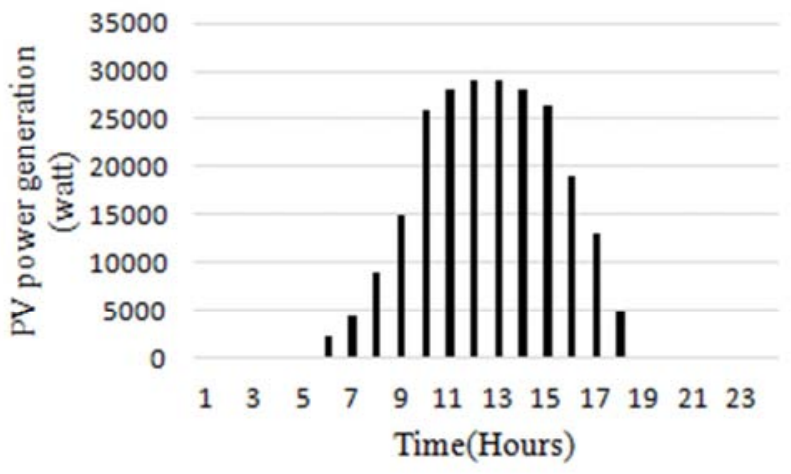

Figure 9. Power generation from PV in a typical day.

Modeling and design of the components involved in the topology is carried out in MATLAB Simulink as represented in Figure 7. It depicts a charging station with charging posts where the sources of power: PV, Grid and BESS injects power for charging of the vehicles plugged in the charging posts.

\subsection{Modeling of EV Loads}

The load demand in the charging station varies continuously and accurate load forecasting is very difficult as the load demand by the EV depends on many factors including activities and driving pattern of vehicle owner. Furthermore, instantaneous power demand depends on the numbers of simultaneous EVs plugged in a typical day is assumed to be varying as shown in Figure 8. The load modeling is based on the experiment data of a typical march day as presented in [26]. Figure depicts the variation of number of electrical vehicles with time of a day. For the modeling, a charging station is assumed with 15 charging posts (CPs) and the numbers of electric vehicles in the figure commensurate the numbers of CPs where the EVs are plugged in at a time. During the day time, from $10 \mathrm{pm}$ to 4 pm, there are abundant if EVs seen on the street being driven; that's why, few EVs could be seen in the charging station. On the contrary, the charging station could be found rife with electric vehicle in the evening; That needs all its CPs to be used. Similarly, in the very morning time the EV owners tend to make their vehicles ready for driving over the day: they charge their EVs to a healthy state of charge (SOC). That's why the charging station could be found somewhat plenty with EVs during morning too.

Regarding the modeling of EV loads in the MATLAB, a Simulink model is used with battery with the specifications presented in Table 2. The specifications of each electric vehicles are taken from reference [27]. Here, level 2 charging of battery is used in which the EV is provided with $240 \mathrm{~V} \mathrm{dc}$ input and current of $15 \mathrm{~A}$ which is regarded as a fast charging. Since, Li-ion batteries are prominently used in the Electric vehicles; so, it is used in the Simulink model which acts as an electric vehicle and draws power from the CPs of DC-link.

Table 2. Battery Specification of EV.

\begin{tabular}{ll}
\hline Parameters & Descriptions \\
\hline Electric vehicle model & Nissan Leaf BGV \\
Battery Type and Energy & Li-ion 24kWh \\
All-electric range & $118 \mathrm{Km}$ \\
Charging/discharging efficiency (Level 2 charging) & $92 \%$ \\
Power rating & $4 \mathrm{~kW}$ \\
\hline
\end{tabular}

\subsection{Design of PV, BESS and Grid}

\subsubsection{Photovoltaic Array}

The power output from the PV depends on irradiance and temperature conditions. The model of PV array available in MATLAB is used and is operated with various values of temperature and irradiances. Number of modules connected in series and parallel determines its rating (maximum power). PV array is modeled with rating such that it could provide the base load demand in the charging station, which is estimated to be $28 \mathrm{~kW}$. For providing base load, $8 \times 17 \mathrm{PV}$ panel with the maximum output voltage and current rating of $\mathrm{PV}$ is $240 \mathrm{~V}$ and 
$120 \mathrm{~A}$ is used. The PV array is connected to the DC link via boost converter with PID control to match the voltage output of PV with DC link voltage. Another purpose of using PID controller is that it makes converter output voltage follow the reference voltage provided by load sharing algorithm. Figure 9 depicts the variation of power generation from PV over the day based on temperature and irradiance data. It shows that PV generates maximum power of $28 \mathrm{~kW}$ during the mid-day which is equal to the base load required to be supplied. In other time there is no power generation from $\mathrm{PV}$.

\subsubsection{Battery Energy Storage System}

the Battery storage system should provide the base power demand of $28 \mathrm{~kW}$ during the peak load period. The rating of storage should be $140 \mathrm{kWh}$ for providing load continuously up to 5 hours when full charged. BESS is connected to the DC link via its boost converter along with PID controller in the same way as PV is connected. The charging and discharging of the battery are controlled though a switch operated by power management algorithm.

\subsubsection{Grid}

Grid delivers the peak demand in case of availability of PV and storage, and supplies all load demands when base power supplying units do not have enough power. A three-phase step-down transformer is suggested to deliver the load via controlled rectifier backed by dc-dc converter to improve power factor. kVA rating of transformer is to be equivalent to peak power demand from the grid. For the simulation, three phase voltage source of $240 \mathrm{~V}$ has been used as a grid.

\section{Results and Economic Analysis}

\subsection{Simulation Results}

The proposed topology is simulated in MATLAB. EV load profile at different times of days is the key point for the selection of sources for the supply of their demand. The algorithm modeled in MATLAB determines the sources to be made on at certain time. Figure 10 shows the estimation of load demanded by EVs at a particular day. The peak demand of EV is assumed to be $54 \mathrm{~kW}$ from 7:00 pm to 9:00 pm in a typical day. The base load is assumed to be $28 \mathrm{KW}$. So, the rating of PV and BESS is chosen $28 \mathrm{KW}$ each. The algorithm determines the sources to be selected as per the load demand by electric vehicle which will be verified in this section.

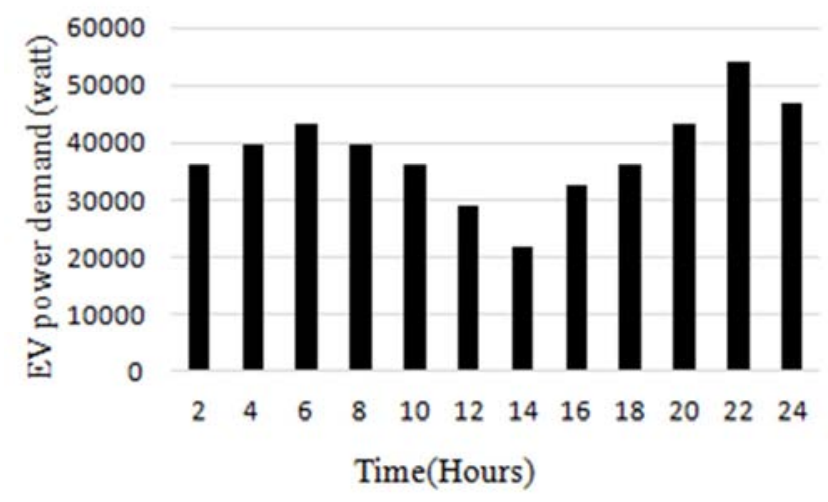

Figure 10. Load demand profile of electric vehicles in a typical day.

Figure 11 (a) illustrates the load shared by PV, BESS and Grid for charging of EV during morning: 7 am to $10 \mathrm{am}$. In the morning before the PV starts generating power, Grid supplies all the load demand of EV as depicted in the figure. When PV starts generating power, its power has to be fully utilized and priority has to be given to the PV over Grid for supplying EVs. The load shared by Grid goes on waning and load shared by PV goes on waxing due to increasing PV power generation when the intensity of the Sun goes on increasing (considering a day with clear sky). PV delivers all its power generation for charging of EVs at some point of the day when the EV load demand does not exceed the PV power generation. There is no need of BESS during this time because the Grid power is supported by PV.

Figure 11 (b) depicts the load shared by the sources during the day: 10 am to $5 \mathrm{pm}$. PV provides all its generated power during the day assuming the sun intensity is good. Whenever the power demand by EVs becomes lower than the power generated by PV during day, BESS is charged with excess power of PV. In the Figure charging of BESS is represented by the negative value of power curve of BESS. Energy from $\mathrm{PV}$ is not available during night time and it produces its maximum rated power only few hours a day as illustrated in the figure. In the time when PV power is not sufficient to provide the load demand (in the late afternoon), Grid combines with the PV and shares the load with PV as illustrated by the rising curve of Grid and falling curve of PV.

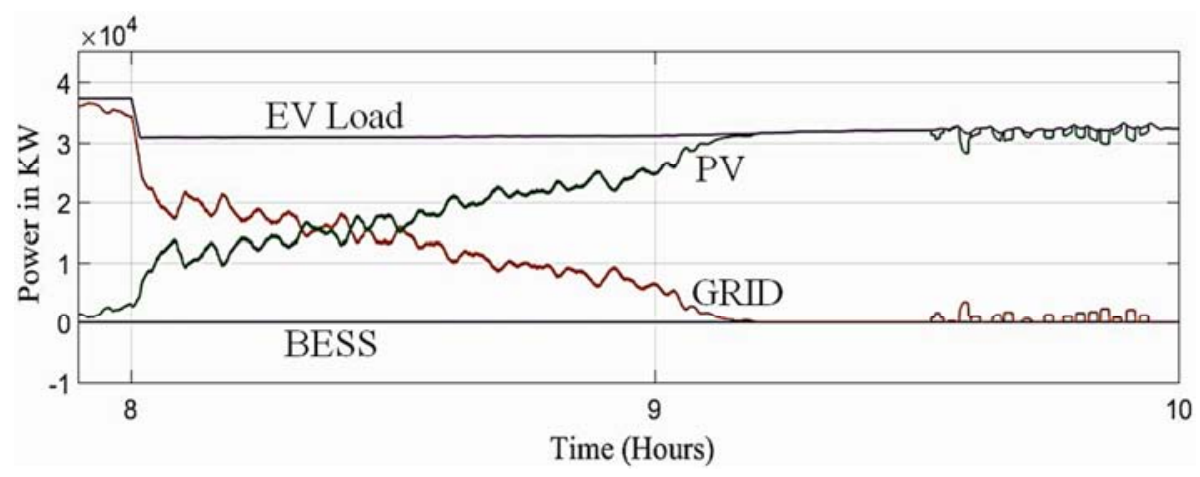

(a) 


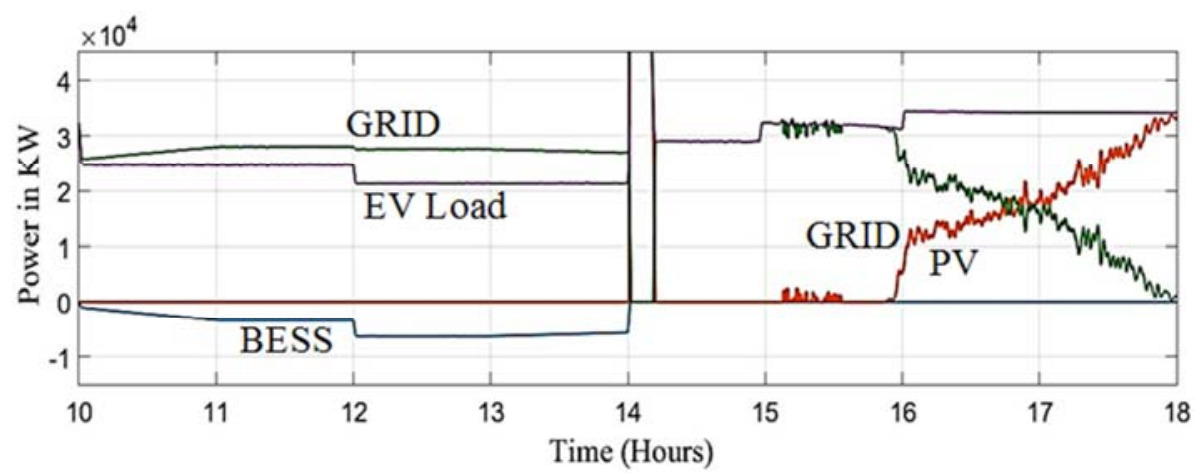

(b)

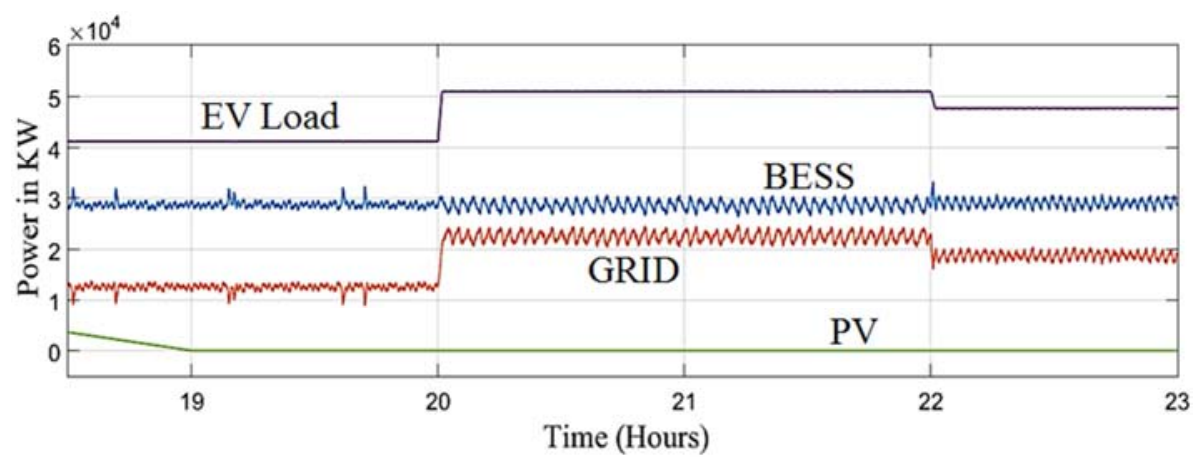

(c)

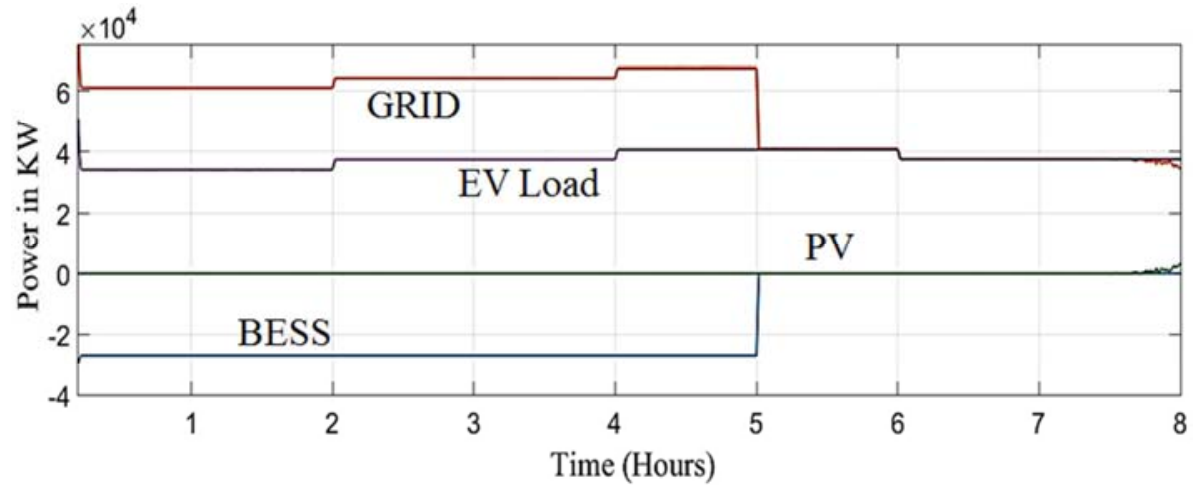

(d)

Figure 11. Load Shared by PV, BESS and Grid for charging of EV during (a) 7:00 am to 10:00 am: morning, (b) 10:00 am to 5:00 pm: day, (c) 5:00 pm to 11:00pm: evening and peak-time, (d) 11:00 pm to 5:00 am: super off-peak time.

Figure 11 (c) depicts the primary focus of the work. During the evening time $(6 \mathrm{pm}-11 \mathrm{pm})$ when the peak power demand occurs both in the normal electricity load profile of the grids and that of charging station. PV power is unavailable during this time; that's why, load demand of the vehicles has to be supplied by the Grid and it obviously increases the stress on the grid. During this peak period, BESS discharges to share the load with Grid so as to reduce the stress on it. The figure shows that during peak period, the BESS shares the part of load equivalent to its rating which is for simulation assumed to be $28 \mathrm{KW}$, the base load. Remaining power is supplied by Grid. This implies that the grid power consumption reduces significantly during the peak time.

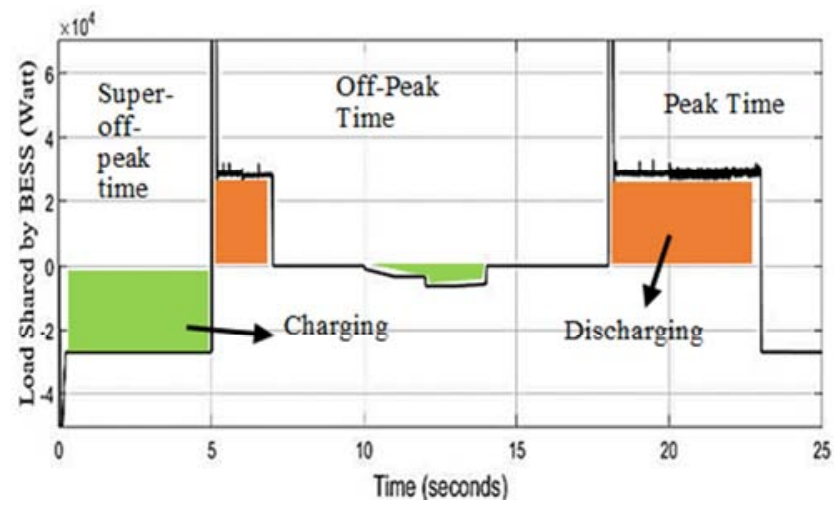

Figure 12. Load profile of Charging and Discharging of BESS. 


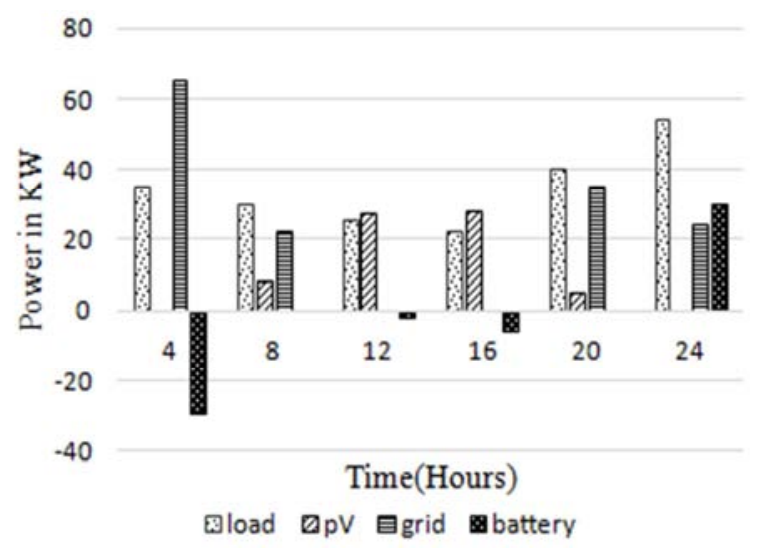

Figure 13. Summary of Load Profiles of PV, BESS and Grid over a Day.

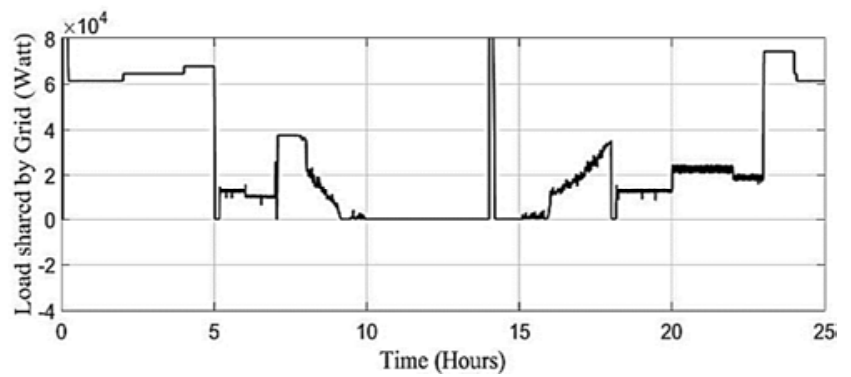

Figure 14. Power Supplied by Grid for EV charging.

Figure 11 (d) depicts the load profile of the system during the very morning time: $11 \mathrm{pm}-5 \mathrm{am}$. During this period, load profile of the normal electricity shows the lowest of its power consumption. That's why grid is used to charge the electric vehicle as well as to innervate the BESS. This shows large power consumption on the Grid but do not contribute the stress on the grid. The negative power profile of the BESS in the figure shows the charging of the BESS. The figure does not maintain the charging of BESS up to 5 am at any cost. The BESS need to be kept ready for the contribution to the upcoming peak period.

Figure 12 represents the load profile of BESS, which illustrates the charging and discharging power profile of energy storage system. It illustrates that the BESS is charged during the off-peak time when tariff rate is significantly lower (between 11pm-5am). Charging can also be performed from PV power in the day time when the load power is less than PV power. It is discharged during peak hours from 6:00pm to $11: 00 \mathrm{pm}$ in order to reduce the stress on the grid. During the peak hours, BESS is given more priority to supply the load, i.e. base load $28 \mathrm{KW}$ is supplied by battery and remaining load is supplied by the Grid. In the figure, positive BESS power represents the discharging of BESS, whereas negative power indicates the charging of battery.

Figure 13 shows the load profiles of sources. It shows in the very morning; Grid power supply is greater than EV demand. This indicates extra power from the grid is used to charge BESS. Here, negative power indicates charging of battery. Likewise, in the mid-day, Grid power is very small or zero due to high power contribution by PV. In the peak load demand, BESS shares significant loads and hence reduces the stress in the grid. The simulation results clarify that EV load demands are fulfilled by prioritizing the sources on the basis of power management algorithm.

\subsection{Economic Analysis of the Feasibility of the System}

The investment on the installation of the PV in the charging station is based on the specific value of PV installation: $\$ 3.5$ per $\mathrm{kW}$. Since the rating of $\mathrm{PV}$ for the proposed system is $28 \mathrm{~kW}$, the installation cost of PV is $\$ 98,000$. Similarly, investment on the BESS is based on the specific cost of BESS per kWh: \$200. Hence, investment for the BESS of $140 \mathrm{kWh}$ capacity becomes $\$ 28,000$. Hence total extra investment to be made for the proposed system will be $\$ 126,000$. The daily cost of electricity the station should pay to the Grid before the installation of PV and BESS can be found out in Table 3:

Table 3. Calculation of Grid-Electricity bill before installation of $P V$ and BESS.

\begin{tabular}{llll}
\hline Time of Day & Rate $\mathbf{( \$ / k W h )}$ & kW consumed & Price $\mathbf{( \$ )}$ \\
\hline $12 \mathrm{am}-2 \mathrm{am}$ & 0.101 & 34 & 6.868 \\
$2 \mathrm{am}-4 \mathrm{am}$ & 0.101 & 38 & 7.676 \\
$4 \mathrm{am}-6 \mathrm{am}$ & 0.101 & 42 & 8.484 \\
$6 \mathrm{am}-8 \mathrm{am}$ & 0.144 & 38 & 10.944 \\
$8 \mathrm{am}-10 \mathrm{am}$ & 0.144 & 29 & 8.352 \\
$10 \mathrm{am}-12 \mathrm{pm}$ & 0.144 & 24 & 6.912 \\
$12 \mathrm{pm}-2 \mathrm{pm}$ & 0.144 & 20 & 5.76 \\
$2 \mathrm{pm}-4 \mathrm{pm}$ & 0.144 & 28 & 8.064 \\
$4 \mathrm{pm}-6 \mathrm{pm}$ & 0.144 & 32 & 9.216 \\
$6 \mathrm{pm}-8 \mathrm{pm}$ & 0.208 & 42 & 17.472 \\
$8 \mathrm{pm}-10 \mathrm{pm}$ & 0.208 & 54 & 22.464 \\
$10 \mathrm{pm}-12 \mathrm{am}$ & 0.208 & 46 & 19.136 \\
Total & & 427 & 131.348 \\
\hline
\end{tabular}

Now the daily cost of electricity can be found out from the profile of load shared by grid as shown in Figure 14 when PV and BESS are introduced in the system. Table 4 shows the calculation involved.

Table 4. Calculation of Grid-Electricity bill after installation of PV and BESS.

\begin{tabular}{llll}
\hline Time of Day & Rate $\mathbf{( \$ / k W h )}$ & kW consumed & Price $\mathbf{( \$ )}$ \\
\hline 12 am-2 am & 0.101 & 62 & 12.524 \\
2 am-4 am & 0.101 & 65 & 13.13 \\
4 am- 5 am & 0.101 & 68 & 6.868 \\
5 am- 8 am & 0.144 & 12 & 5.184 \\
8 am-10 am & 0.144 & 15 & 4.32 \\
10 am-12 pm & 0.144 & 0 & 0 \\
12 pm-2 pm & 0.144 & 0 & 0 \\
2 pm-4 pm & 0.144 & 0 & 0 \\
4 pm-6 pm & 0.144 & 20 & 5.76 \\
6 pm-8 pm & 0.208 & 13 & 5.408 \\
8 pm-10 pm & 0.208 & 23 & 9.568 \\
10 pm- 12 am & 0.208 & 20 & 8.32 \\
Total & & & 71.082 \\
\hline
\end{tabular}

When the above calculations are juxtaposed, following information can be conferred:

Reduction in daily operating cost $=\$ 131.348-\$ 71.082$

$=\$ 60.266$ 
Percentage reduction in operating $\cos \mathrm{t}=60.266 / 131.348$

$$
\approx 46 \%
$$

Thus, the operating cost of the charging station can be decreased nearly by $46 \%$ when the BESS and PV are added. Now, for the feasibility analysis of the system, we have to analyze payback period method:

The daily revenue $=\mathrm{kWh}$ consumed by EVs over 24 Hours $\times$ tariff rate $=(34+38+42+38+29+24+20+28+32+42+54+46)$

$$
\times 2 \times(\$ 0.151 \text { per } \mathrm{kWh})=427 \times 2 \times 0.151=\$ 128.954
$$

The daily $\cos t=$ Grid-electricity Bill (neglecting maintenance cost and all of the other probable costs $)=\$ 71.082$

The daily profit to the station $=\$ 128.954-\$ 71.082$

$$
=\$ 57.872
$$

Therefore, approximate annual profit $=\$ 57.872 \times 365$

$$
=\$ 21123
$$

$$
\text { Simple payback period }=\frac{126000}{21123}=5.96 \approx 6 \text { years }
$$

Thus, the investment made on PV and BESS will be recovered after 6 years. This implies that the financial feasibility of the proposed system can be realized. This analysis can be expounded further with all necessary factors realizing the lifetime of the PV and BESS which are neglected here for the simplicity of economic analysis.

\section{Conclusion}

Proposed power flow management techniques for charging of electric vehicle has been presented in this paper. The objective of the proposed technique is to design a topology which supports fast charging of electric vehicles by the penetration of $\mathrm{PV}$, and BESS into the grid, which significantly reduces the stress in the grid caused by fast charging. The proposed idea is implemented by modeling EV loads profiles and prioritizing the sources accordingly in order to fulfill all the power demand of the EV loads. Application of droop regulation method is implemented for the effective load sharing by different sources. This work implies that the penetration of renewable energy sources onto the grid for EV charging can reduce the effects on the electricity grids, caused by high power consumption for fast charging of EVs. Furthermore, the addition of RES reduces the grid-electricity bill which helps generate profit to the charging station and this profit consequently helps to return the investment made on RES.

\section{References}

[1] D. Sperling and M. A. Deluchi, Transportation energy futures. 1989.

[2] O. US EPA, "Greenhouse Gas Emissions from a Typical Passenger Vehicle."
[3] Z. Moghaddam, I. Ahmad, D. Habibi, and Q. V. Phung, "Smart Charging Strategy for Electric Vehicle Charging Stations," IEEE Trans. Transp. Electrif., vol. 4, no. 1, pp. 7688, 2017.

[4] M. R. A. Ashish Kumar Karmaker, Sujit Roy, "Analysis of the impacts of Electric Vehicle Charging Station in Bangladesh," ECCE, IEEE Conf., pp. 7-9, 2019.

[5] M. Yilmaz and P. T. Krein, "Review of the impact of vehicleto-grid technologies on distribution systems and utility interfaces," IEEE Trans. Power Electron., vol. 28, no. 12, pp. 5673-5689, 2013.

[6] A. Malhotra, N. Erdogan, G. Binetti, I. D. Schizas, and A. Davoudi, "Impact of Charging Interruptions in Coordinated Electric Vehicle Charging," Department of Electrical Engineering, University of Texas at Arlington, Arlington, Texas, 76010 USA Department of Electrical and Information Engineering, Polytechnic University,” pp. 901-905, 2016.

[7] W. Kempton and J. Tomić, "Vehicle-to-grid power implementation: From stabilizing the grid to supporting largescale renewable energy," J. Power Sources, vol. 144, no. 1, pp. 280-294, 2005.

[8] W. Kempton and J. Tomić, "Vehicle-to-grid power fundamentals: Calculating capacity and net revenue," $J$. Power Sources, vol. 144, no. 1, pp. 268-279, 2005.

[9] J. A. P. Lopes, P. M. R. Almeida, and F. J. Soares, "Using vehicle-to-grid to maximize the integration of intermittent renewable energy resources in islanded electric grids," 2009 Int. Conf. Clean Electr. Power, ICCEP 2009, pp. 290-295, 2009.

[10] N. Erdoğan, F. Erden, and T. Altun, "Coordinated Electric Vehicle Charging Strategy in Microgrids Containing PV System," vol. 4, no. 1, pp. 9-21, 2017.

[11] J. García-Villalobos, I. Zamora, J. I. San Martín, F. J. Asensio, and V. Aperribay, "Plug-in electric vehicles in electric distribution networks: A review of smart charging approaches," Renew. Sustain. Energy Rev., vol. 38, pp. 717-731, 2014.

[12] M. O. Badawy and Y. Sozer, "Power Flow Management of a Grid Tied PV-Battery System for Electric Vehicles Charging," IEEE Trans. Ind. Appl., vol. 53, no. 2, pp. 1347-1357, 2017.

[13] A. Ul-Haq, M. Azhar, Y. Mahmoud, A. Perwaiz, and E. A. AlAmmar, "Probabilistic modeling of electric vehicle charging pattern associated with residential load for voltage unbalance assessment," Energies, vol. 10, no. 9, pp. 1-18, 2017.

[14] C. Balakishan, N. Sandeep, and M. V Aware, "Design and Implementation of Three-Level DC-DC Converter with Golden Section Search Based MPPT for the Photovoltaic Applications Design and Implementation of Three-Level DCDC Converter with Golden Section Search Based MPPT for the Photovoltaic Applicatio," no. March 2015, 2016.

[15] A. Hassoune, M. Khafallah, A. Mesbahi, and T. Bouragba, "Power management strategies of electric vehicle charging station based grid tied PV-battery system," Int. J. Renew. Energy Res., vol. 8, no. 2, pp. 851-860, 2018.

[16] "Electricity Load profile of Nepal in 2073 Chaiitra | Nepal Electricity Authority - Datasets - Open Data Nepal." [Online]. Available: http://opendatanepal.com/dataset/electricity-loadprofile-of-nepal-in-2073-chaiitra-nepal-electricity-authority. [Accessed: 22-Dec-2019]. 
[17] P. Chaudhari, M. Khadse, V. Jadhav, P. Patil, and K. Daware, "Novel Control Strategy for Dynamic Load Sharing Between DC-DC Converters for DC Microgrid," vol. 2, no. 6, pp. 3-7, 2015.

[18] A. Tah and D. Das, "An Enhanced Droop Control Method for Accurate Load Sharing and Voltage Improvement of Isolated and Interconnected DC Microgrids," IEEE Trans. Sustain. Energy, vol. 7, no. 3, pp. 1194-1204, 2016.

[19] M. Mokhtar, M. I. Marei, and A. A. El-Sattar, "An adaptive droop control scheme for DC microgrids integrating sliding mode voltage and current controlled boost converters," IEEE Trans. Smart Grid, vol. 10, no. 2, pp. 1685-1693, 2019.

[20] K. Zhang et al., "Optimal Charging Schemes for Electric Vehicles in Smart Grid: A Contract Theoretic Approach," IEEE Trans. Intell. Transp. Syst., vol. 19, no. 9, pp. 30463058, 2018.

[21] R. M. Thomas and D. Jose, "Control Method for Parallel DCDC Converters used in Standalone Photovoltaic Power System."
[22] M. L. Hagge, "Engineering Economic Analysis of Solar Pv Installations Considering Power Conversion Alternatives," 2016.

[23] A. D. Bank, Handbook on Battery Energy Storage System, no. December. 2018.

[24] "Time-of-Use Rates." [Online]. Available: http://www.ieso.ca/en/Power-Data/Price-Overview/Time-ofUse-Rates. [Accessed: 22-Dec-2019].

[25] "The Price Of Electricity In Your State : Planet Money : NPR," NPR, 2011. [Online]. Available: https://www.npr.org/sections/money/2011/10/27/141766341/t he-price-of-electricity-in-your-state. [Accessed: 22-Dec-2019].

[26] W. Kuihua, N. Xinsheng, W. Jian, W. Kuizhong, and J. Shanjie, "Electric Vehicle Load Characteristic Analysis and Impact of Regional Power Grid," pp. 257-261, 2012.

[27] M. Karki and J. G. Singh, “An Approach to Enhance Battery Life of Gridable Vehicles and the Transformer Life in an Active Distribution System Using PSO,” no. April 2017. 